\title{
Design and Implementation of 8051 Single-Chip Microcontroller for Stationary 1.0 kW PEM Fuel Cell System
}

\author{
Pei-Hsing Huang, ${ }^{1}$ Jenn-Kun Kuo, ${ }^{2}$ and Yuan-Yao Hsu ${ }^{2}$ \\ ${ }^{1}$ Department of Mechanical Engineering, National Pingtung University of Science and Technology, Pingtung 912, Taiwan \\ ${ }^{2}$ Department of Greenergy, National University of Tainan, Tainan 70005, Taiwan
}

Correspondence should be addressed to Jenn-Kun Kuo; jenn.kun@gmail.com

Received 19 May 2014; Accepted 12 June 2014; Published 15 July 2014

Academic Editor: TianHu Wang

Copyright (c) 2014 Pei-Hsing Huang et al. This is an open access article distributed under the Creative Commons Attribution License, which permits unrestricted use, distribution, and reproduction in any medium, provided the original work is properly cited.

Proton exchange membrane fuel cells (PEMFCs) have attracted significant interest as a potential green energy source. However, if the performance of such systems is to be enhanced, appropriate control strategies must be applied. Accordingly, the present study proposes a sophisticated control system for a 1.0 kW PEMFC system comprising a fuel cell stack, an auxiliary power supply, a DC-DC buck converter, and a DC-AC inverter. The control system is implemented using an 8051 single-chip microcontroller and is designed to optimize the system performance and safety in both the startup phase and the long-term operation phase. The major features of the proposed control system are described and the circuit diagrams required for its implementation introduced. In addition, the touch-sensitive, intuitive human-machine interface is introduced and typical screens are presented. Finally, the electrical characteristics of the PEMFC system are briefly examined. Overall, the results confirm that the single-chip microcontroller presented in this study has significant potential for commercialization in the near future.

\section{Introduction}

Energy consumption around the world has increased astronomically in recent decades as a result of a burgeoning population, the demand for a higher quality of life, and the arrival of new generation technologies, most of which require a reliable and sustainable energy supply [1]. In some overpopulated countries, such as India, there exists a dearth of power-generating resources, and conventional centralized power generation units are incapable of meeting rising power demands. As a result, many cities face the problems of load shedding, brownouts, and even blackouts [2]. One potential solution for tackling these problems is to generate power in a distributed manner, in which electricity is produced by a large number of small-to-medium sized power plants, rather than a centralized large-capacity power plant.

The generation of power in a conventional manner requires the combustion of hydrocarbon-rich fossil fuels such as coal, oil, and natural gas. However, as the world's energy demand continues to increase, these natural resources are being rapidly depleted. Moreover, the combustion of hydrocarbon-rich fuels releases carbon dioxide into the atmosphere, thereby contributing to the global warming effect [3]. Therefore, in developing distributed generation systems, the use of green energy resources such as fuel cells, photovoltaic arrays, wind turbines, microturbines, ultra capacitors, batteries, and flywheels has attracted significant attention [4].

Amongst these various technologies, proton exchange membrane fuel cells (PEMFCs), which produce electrical energy via the electrochemical reaction of air and hydrogen, have attracted particular interest since they produce only water and heat as byproducts and are characterized by a high efficiency, low noise, and a low operating temperature [5]. A typical PEMFC system comprises a fuel cell stack, a fuel feed system, an auxiliary power supply, a cooling system, a power conversion system, and so on. In practice, these components are characterized by a highly complex system of interdependencies. Thus, PEMFCs are most conveniently analyzed using some form of numerical modeling technique. Costa and Camacho [6] constructed a dynamic electrochemical model of a PEMFC stack and then used the model to predict 
the output voltage, efficiency, and power of the stack as a function of the load current. Del Real et al. [7] developed a semiempirical formulation for predicting the fluid dynamics within a 1.2 kW PEMFC. Tirnovan et al. [8] presented a combined empirical and mathematical model for predicting the $V-J$ curves of a PEMFC as a function of the stack temperature and partial oxygen pressure. Kuo and Chen [9] performed a numerical investigation into the gas flow characteristics, temperature distribution, electrochemical reaction efficiency, and electrical performance of a PEMFC with a novel wavelike gas flow channel.

The performance of a PEMFC is affected by many factors, including the operating temperature, the pressure, and relative humidity of the inlet gases, the transport characteristics of the reactants and byproducts, the dissipation of the reaction heat, and the purging of unreacted fuel from the cell. If the performance of such systems is to be enhanced, all of these factors must be properly coordinated and controlled [10]. Accordingly, the literature contains many proposals for sophisticated PEMFC control systems. For example, Rgab et al. [11] presented a fuzzy logic controller for a PEMFC stack consisting of 15 cells and showed that the stack could be successfully controlled even under sudden changes in the external electric load. Kim and Peng [12] developed a control scheme for coordinating the dynamics of a PEMFC stack and a DC-DC converter system, respectively, so as to meet the changing demands of an external load. Hajizadeh and Aliakbar-Golkar [13] presented a fuzzy logic scheme for controlling the power conditioning units in standalone PEMFC applications (requiring only DC-DC conversion) and grid applications (requiring both DC-DC conversion and DC-AC inversion).

In a recent study by the present group [3], a sophisticated control scheme based on a programmable logic controller (PLC) was proposed for improving the performance and efficiency of a $1.0 \mathrm{~kW}$ prototype PEMFC system. PLC controllers have many advantages, including a low cost, good flexibility, and good reliability. However, PLC controllers require intensive user training and can be implemented only in certain environments (e.g., they cannot be deployed in environments characterized by high temperature or vibration). By contrast, single-chip microcontrollers can not only do all that PLCs can do and more but also have a smaller physical size, a cheaper cost, the potential for mass production, an improved programming flexibility, and so on. As a result, single-chip microcontrollers have been used for many applications in recent years, including electronic locks, voice-activated devices, cleaning robots, and wireless remotecontrolled vehicles [14].

The present study proposes a sophisticated control system based on an 8051 single-chip microcontroller for a $1.0 \mathrm{~kW}$ PEMFC system comprising a fuel cell stack, an auxiliary power supply, a DC-DC buck converter, and a DC-AC inverter. The control scheme is designed to optimize the system performance and safety in both the startup phase and the long-term operation phase. The controller is integrated with a touch-sensitive, intuitive human-machine interface implemented on a notebook (or PC) such that the operational status of the PEMFC system can be easily determined and the operational parameters adjusted if required.

The remainder of this paper is organized as follows. Section 2 briefly describes the $1.0 \mathrm{~kW}$ PEMFC system considered in the present study. Section 3 introduces the proposed 8051 single-chip microcontroller. Section 4 describes the touch-sensitive human-machine interface and briefly examines the electrical performance of the PEMFC system. Finally, Section 5 provides some brief concluding remarks.

\section{Prototype 1.0 kW PEMFC System}

Figure 1 presents a schematic illustration of the prototype $1 \mathrm{~kW}$ PEMFC system. As shown, the major items of equipment include a hydrogen supply system, an air fan, a PEM fuel cell stack, a set of cooling fans, a water tank, a DC-DC buck converter, a DC-AC inverter, an auxiliary power supply, a DC meter, an AC meter, and an 8051 single-chip microcontroller. Figure 2 presents a photograph of the assembled system. The nominal operating parameters of the PEM fuel cell stack are summarized in Table 1.

The stack consists of 60 cells, bundled into 12 segments, with each segment containing 5 cells. On activating the PEMFC system, the startup power is provided by a $24 \mathrm{~V}$ DC rechargeable battery. In the long-term operation phase, the DC output voltage $(30 \sim 48 \mathrm{~V} \mathrm{DC})$ is stepped down to a constant $24 \mathrm{~V}$ DC via a DC-DC buck converter. Part of the $\mathrm{DC}$ voltage is used to recharge the battery and to power various components within the system, while the remainder is converted to a $110 \mathrm{~V}$ AC voltage in order to power smallscale items of electrical apparatus such as fans, computers, and photocopier machines.

\section{8051 Single-Chip PEMFC Control System}

The PEMFC system described in Section 2 is controlled by a sophisticated 8051 single-chip microcontroller. The controller continuously monitors various system parameters (e.g., the inlet gas pressure, stack temperature, DC and AC output voltage, and external power demand) and then instructs appropriate actions as required in order to optimize the system performance and maintain operational safety. For example, if the controller detects an increase in the external power demand, it instructs an increase in the air fan speed in order to increase the amount of air supplied to the stack. Similarly, if the controller detects that the output voltage or stack temperature is beyond the safe range, it triggers an audio and visual warning and shuts the system down if no remedial action is taken within a predetermined period of time.

As shown in Figure 3, the 8051 microcontroller monitors five major aspects of the PEMFC system, namely, (1) the reactant supply system, (2) the PEMFC stack, (3) the DCDC buck converter, (4) the DC-AC inverter, and (5) the external load. It is noted that the microcontroller is physically situated within the PEMFC system but is interfaced to the user by means of a notebook (or PC). This section commences by describing two fundamental components of the PEMFC control scheme, namely, the reactant supply system and the 


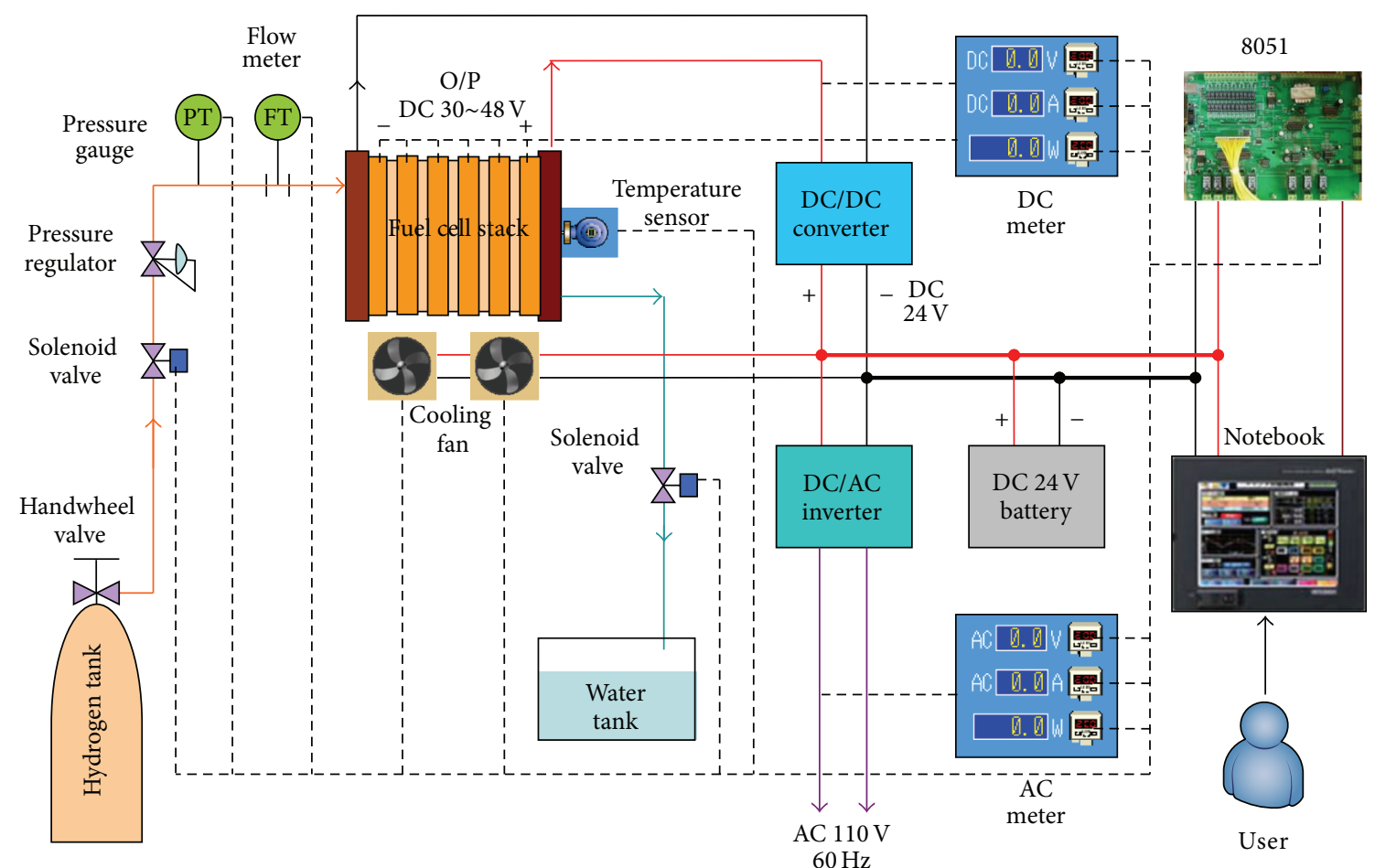

FIgURE 1: Schematic illustration of 1.0 kW PEMFC system.

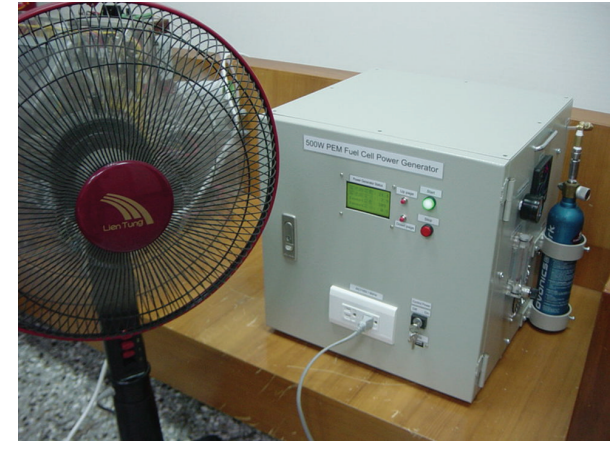

(a)

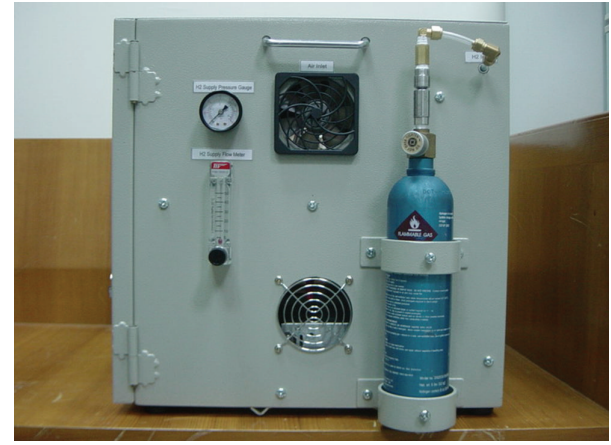

(b)

FIGURE 2: Photograph of prototype $1.0 \mathrm{~kW}$ PEMFC system.

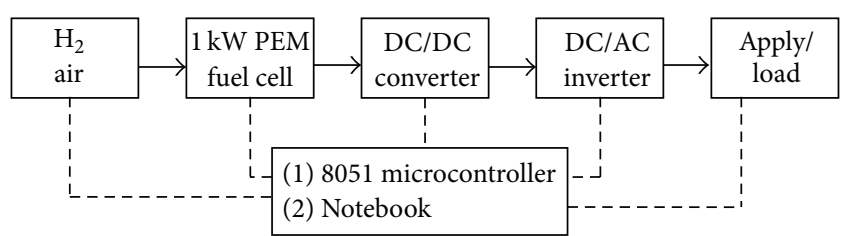

FIGURE 3: Block diagram of intelligent control system for PEMFC system.

power conditioning unit (i.e., the DC-DC converter and the DC-AC inverter). The overall operational flow of the control system in the startup phase and the long-term operation phase is then briefly described. Finally, the circuit diagrams required for the implementation of the 8051 microcontroller are presented.

3.1. Reactant Supply System. In the prototype PEMFC fuel cell system considered in the present study, the stack is supplied with hydrogen and clean air with a relative humidity (RH) of more than $80 \%$. On system startup (or reset), the controller instructs the air fan to run at full power for a short period of time $(20 \mathrm{sec})$ in order to purge any water and/or inert gas from the stack. During long-term operation, the pressure (supply rate) of the hydrogen fuel is fixed at $150 \mathrm{kPa}$ (see Table 1). However, the flow rate of the oxidant (air) is varied adaptively via a PID controller in response to changes in the external load so as to maintain a constant stoichiometric ratio of 2.5 . 
TABLE 1: Nominal data of prototype 1.0 kW PEMFC stack.

\begin{tabular}{lc}
\hline Specification & \\
\hline Number of cells & 60 \\
Nominal power (at $0.7 \mathrm{~V} /$ cell) & $0.8 \mathrm{~kW}$ \\
Nominal voltage & $37 \mathrm{~V}$ \\
Nominal current & $27 \mathrm{~A}$ \\
Peak power $($ at $0.6 \mathrm{~V} / \mathrm{cell})$ & $1.0 \mathrm{~kW}$ \\
Active area $\left(\mathrm{cm}^{2}\right.$ ) & $100 \mathrm{~cm}^{2}$ \\
\hline Operational conditions & \\
Anode (pure $\mathrm{H}_{2}$ ) & \\
$\quad$ Pressure & $150 \mathrm{kPa}$ \\
Temperature & $25^{\circ} \mathrm{C}$ \\
$\quad$ Relatively humidity & $100 \%$ \\
Cathode (air) & \\
$\quad$ Pressure & Ambient pressure \\
Temperature & $25^{\circ} \mathrm{C}$ \\
Relatively humidity & $100 \%$ \\
Stoichiometric ratio & 2.5 \\
\hline
\end{tabular}

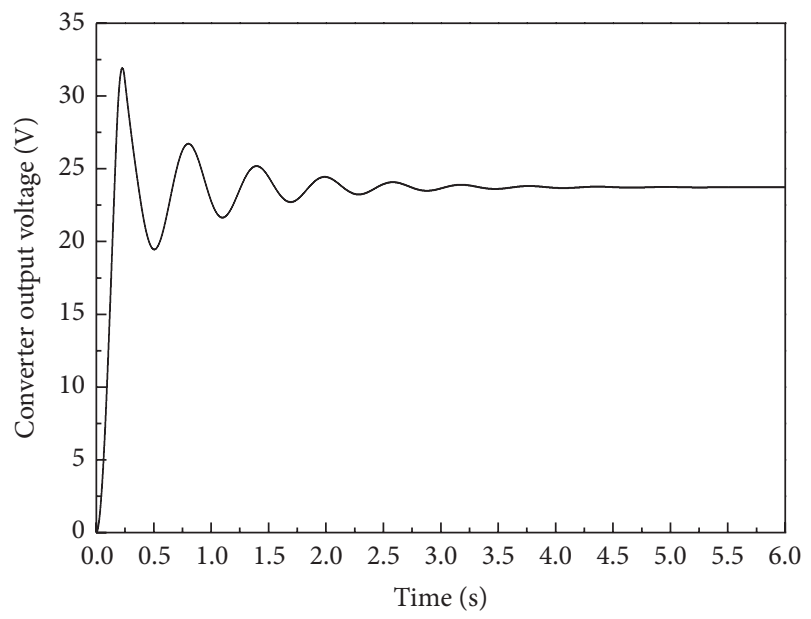

FIGURE 4: Output voltage of DC-DC buck converter.

3.2. Power Conditioning Unit. As shown in Figure 1, the output voltage of the fuel cell stack varies dynamically in the range of $30 \sim 48 \mathrm{~V} \mathrm{DC}$. To be of practical use, this voltage must be regulated in some way so as to meet the power supply requirements of different applications. In the prototype PEMFC system considered in this study, this is achieved by means of a power conditioning unit comprising a DC-DC buck converter and a DC-AC inverter. As shown in Figure 4, the DC-DC converter transforms the unregulated voltage produced by the fuel cell stack into a constant $24 \mathrm{~V} \mathrm{DC}$ voltage (note that this is achieved by monitoring the unregulated voltage produced by the stack and the conditioned voltage produced by the converter and then adjusting the duty ratio of the converter accordingly). As described in Section 2, a small part of the conditioned voltage is used to recharge the auxiliary power supply and to power various DC-based components within the PEMFC system (e.g., the air fan or cooling fans). However, the majority of the $24 \mathrm{~V} \mathrm{DC}$ voltage is processed by a DC-AC inverter to produce a $110 \mathrm{~V}$ AC voltage $(60 \mathrm{~Hz})$ to satisfy the power demands of external electrical devices.

3.3. Operational Flow of 8051 Microcontroller. Figure 5 presents a flowchart showing the operational flow of the 8051 control system during the startup phase. As shown, the system commences by checking the hydrogen pressure. In the event that the pressure is higher than the preset safety level (i.e., $0.6 \mathrm{~kg} \mathrm{~cm}^{-2}$ ), a warning alarm is sounded. The system then checks the nitrogen pressure and again issues an alarm if the pressure is greater than $0.6 \mathrm{~kg} / \mathrm{cm}^{2}$. Having completed the initial checks, the controller instructs a purging of the fuel cell using nitrogen gas in order to expel any residual unreacted hydrogen. Once the preset purge time $(10 \mathrm{sec})$ has elapsed, the controller instructs the supply of hydrogen and air and the PEMFC system enters the warmup phase.

As the stack warms up, the controller instructs a periodic purge of the unreacted hydrogen and activates the cooling fans as required to maintain the stack at the specified operating temperature $\left(85^{\circ} \mathrm{C}\right)$. In addition, the controller continuously monitors the stack output voltage. If the voltage fails to reach the normal operating voltage $(30 \sim 48 \mathrm{~V})$ within the specified warmup time (3 min), a warning signal is issued; else the DC output voltage of the DC-DC converter is used to recharge the auxiliary power supply. Once the battery is fully recharged, the control system transits to the normal longterm operation mode, in which the $24 \mathrm{~V}$ DC output of the $\mathrm{DC}-\mathrm{DC}$ converter is inverted to a $110 \mathrm{~V}$ AC voltage by means of the DC-AC inverter.

Figure 6 presents a flowchart showing the operational flow of the 8051 microcontroller in the normal operation mode. As shown on the left side of the figure, the controller monitors three critical aspects of the system performance, namely, the stack temperature, the stack output current, and the inverter output current. In the event that any of these three operating parameters exceed (or are close to) the maximum permissible values, the controller issues an audible alarm (or warning). As shown in the middle region of the figure, the controller also monitors the output voltage of the DC-AC inverter and issues a warning if the voltage is anything other than the expected output of $110 \mathrm{~V}$ AC. As shown toward the right of the figure, the controller continuously monitors the external load placed on the fuel cell system and adjusts the air fan speed as required to maintain a constant stoichiometric ratio of 2.5 by means of a PID control scheme. Finally, as shown on the right side of the figure, the controller instructs a periodic purging of the fuel cell stack in accordance to the following power-based strategy:

$$
\begin{aligned}
& \mathrm{L}: 0 \mathrm{~W} \leqq \text { output power }<300 \mathrm{~W} \text { purge off } 20 \text { seconds, } \\
& \text { purge on } 0.3 \text { seconds; }
\end{aligned}
$$

M: $300 \mathrm{~W} \leqq$ output power $<600 \mathrm{~W}$ purge off 15 seconds, purge on 0.4 seconds;

$\mathrm{H}: 600 \mathrm{~W} \leqq$ output power $<1000 \mathrm{~W}$ purge off 10 seconds, purge on 0.5 seconds. 


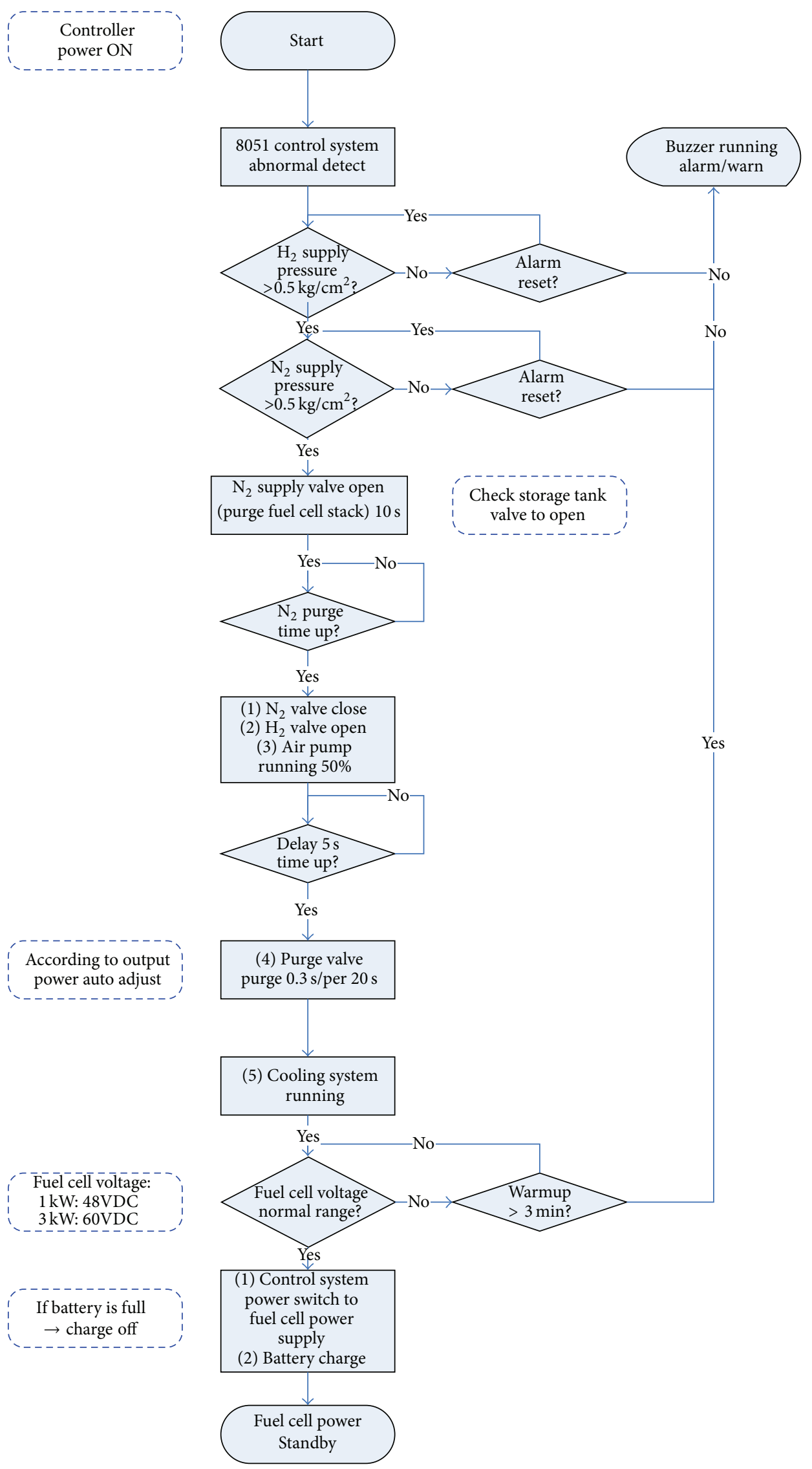

FIGURE 5: Operational flow of 8051 control system during warmup stage. 


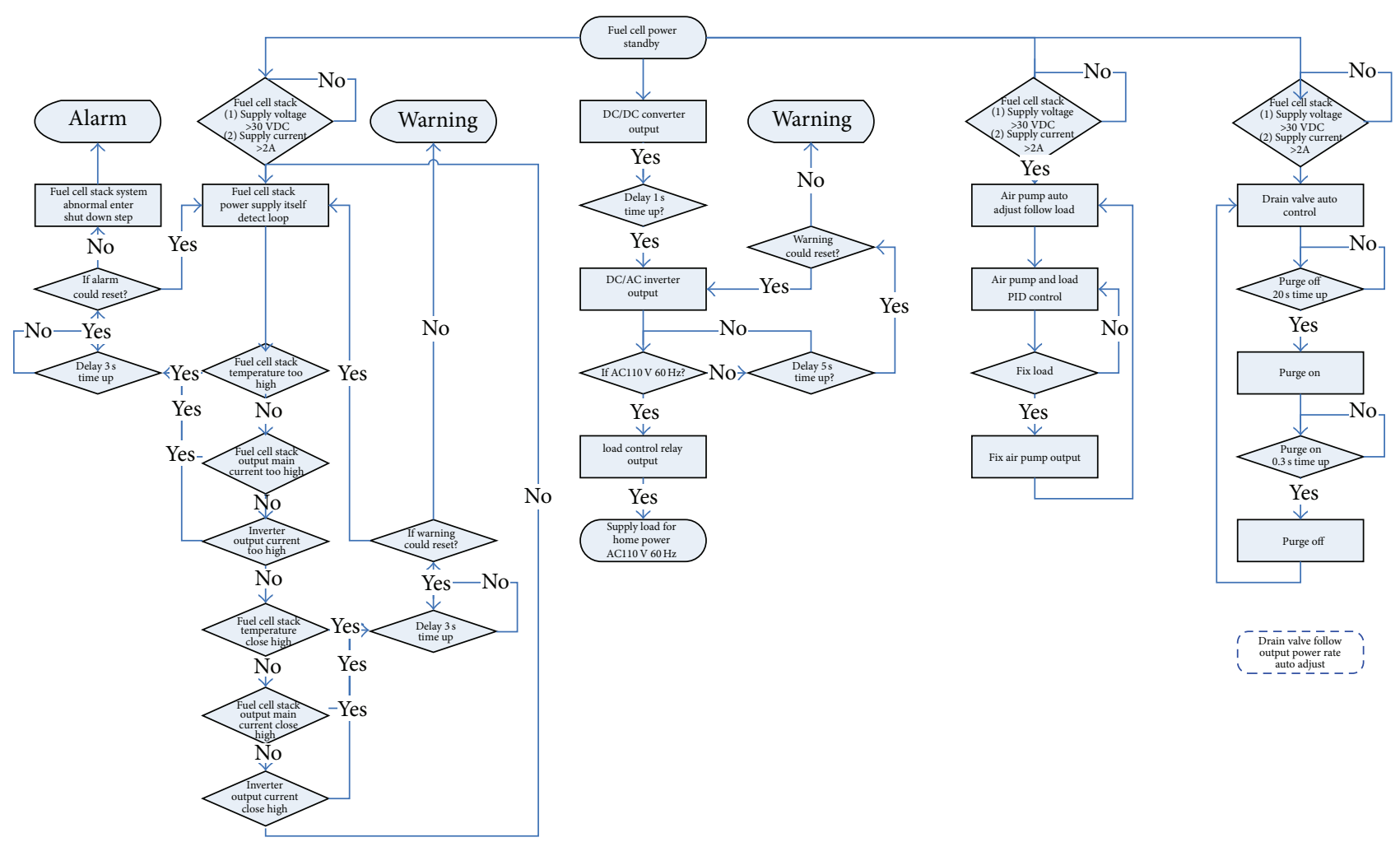

FIgURE 6: Operational flow of 8051 control system during long-term operation phase.

\section{Human-Machine Interface and Electrical Performance of PEMFC}

4.1. Human-Machine Interface. As described in Section 3, the microcontroller is physically situated within the PEMFC system but is interfaced to the user by means of a touchsensitive notebook (or PC). The human-machine interface performs three basic functions. For a general user, the interface provides the means to observe working status (e.g., the pressure, temperature, current, and voltage) at a high mode (e.g., at the stack mode). For a more experienced user or a qualified technician, the interface provides the ability to explore the system status in more detail (e.g., at the cell level), to examine and adjust the system settings as required, and to download the system data for diagnostic purposes. Finally, the human-machine interface permits the 8051 controller to be accessed remotely via the Internet such that maintenance and system adjustments can be carried out by a certified individual.

Figure 7 shows the home screen of the human-machine interface prior to system startup. It is seen that the screen provides a pictorial representation of all the major components within the PEMFC system and indicates the corresponding parameters of interest, for example, the stack temperature; the output voltage, output current, and output power of the fuel cell stack; the output voltage of the DC-DC converter; and the output voltage, current, frequency, and power of the DCAC inverter. Notably, by touching any region of the screen,

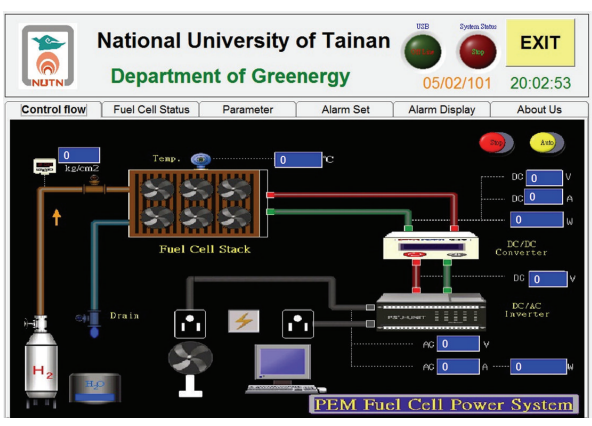

FIGURE 7: Home page of touch-sensitive human-machine interface.

the user can call up a more detailed set of related subscreens in order to analyze the corresponding system component in more detail. For example, Figure 8 shows the subscreen obtained when touching the fuel cell stack region of the home screen. As shown, the screen presents a detailed analysis of the voltage output from each segment of the stack and indicates the corresponding voltage, current, and power (note that the screen shows the prestartup phase, and hence all the system parameters have a value of zero). Figure 9 presents the subscreen provided within the human-machine interface to set the major system parameters, that is, the fuel cell operating temperature, the fuel cell start voltage, the hydrogen purging parameters, and the hydrogen supply pressure. 


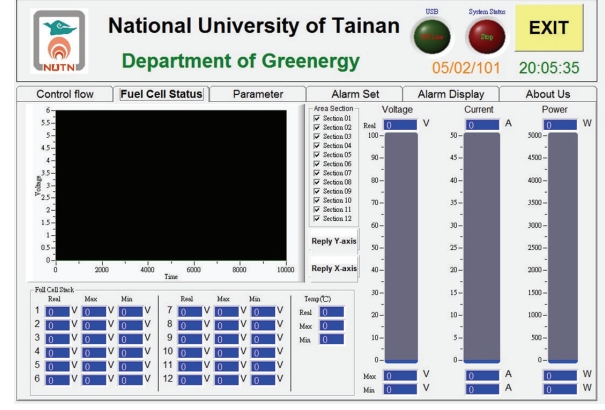

FIGURE 8: Subscreen showing fuel cell status details.

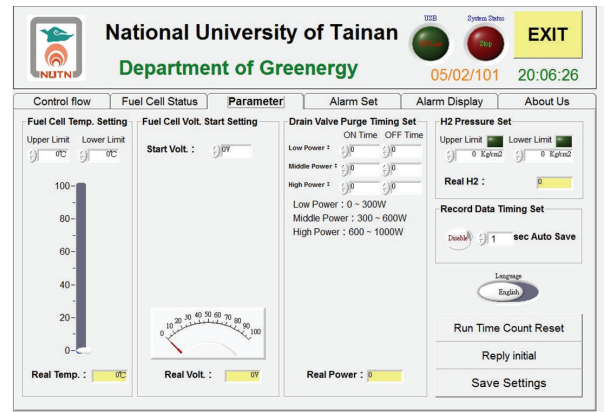

FIGURE 9: Input screen for critical system parameters.

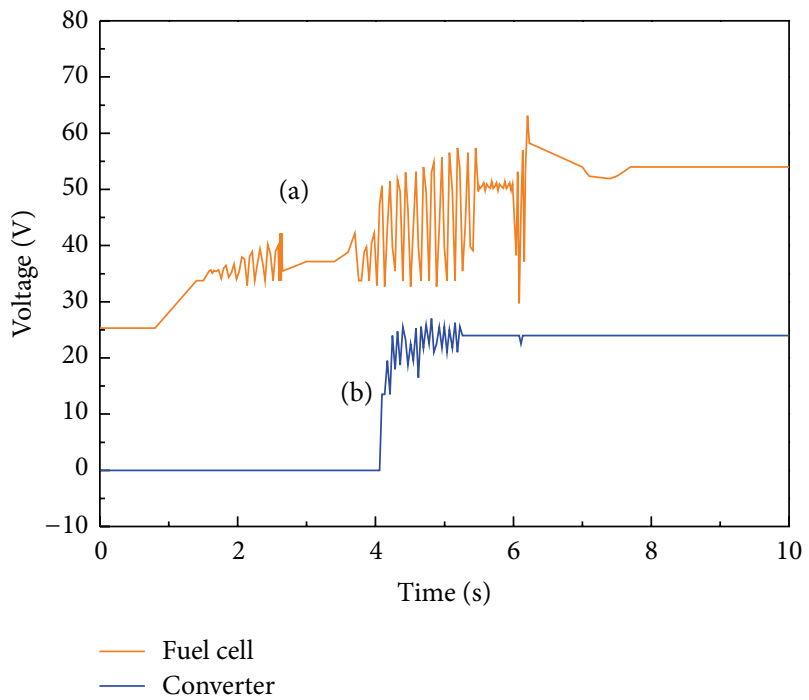

FIGURE 10: Variation of fuel cell stack voltage and DC-DC converter voltage in absence of external load.

4.2. Electrical Performance of Controlled PEMFC System. Figure 10 shows the variation of the fuel cell voltage and DCDC converter voltage during the transition from the system startup phase to the long-term operation phase (note that an external load is not applied). As expected, the fuel cell voltage varies dynamically over the transition period. However, the DC-DC converter successfully stabilizes the output voltage at a value of $24 \mathrm{~V}$ following a period of approximately $6 \mathrm{~s}$.

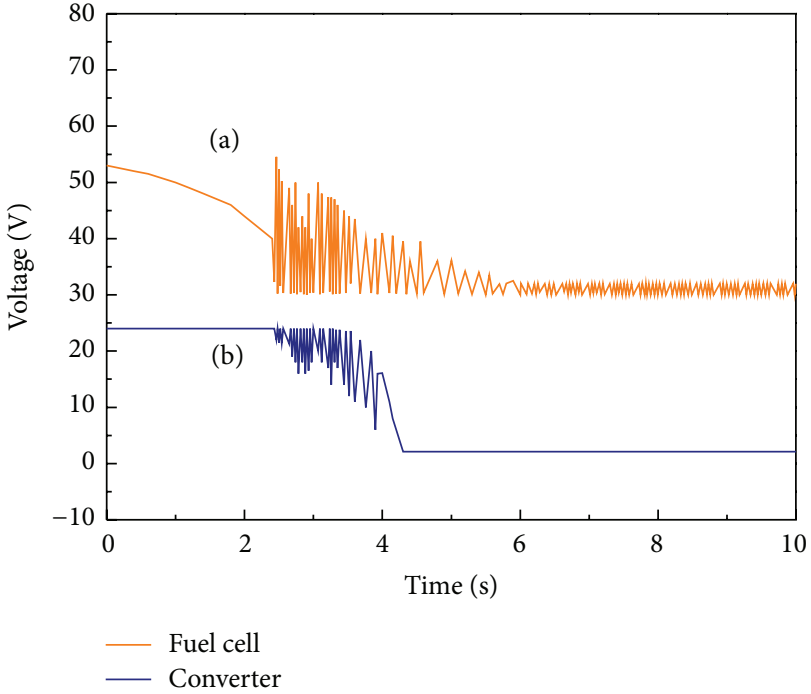

FIGURE 11: Variation of fuel cell stack voltage and DC-DC converter voltage in presence of external load.

Figure 11 shows the variation of the fuel cell voltage and DCDC converter output voltage for the case where an external load is applied. It is seen that the fuel cell voltage fluctuates dramatically under the effects of the external load. However, the ability of the DC-DC converter to maintain a constant output voltage is once again confirmed.

\section{Conclusions}

This study has presented a sophisticated control scheme based on an 8051 single-chip microcontroller for a prototype $1.0 \mathrm{~kW}$ PEMFC system. The operational flow of the control system has been described at a high level and the detailed circuit diagrams required for its implementation have been presented. In addition, the touch-sensitive human-machine interface used to monitor and control the PEMFC system has been introduced. Finally, the electrical performance of the PEMFC system has been briefly examined. Overall, the 8051 single-chip microcontroller proposed in this study has significant potential for low-cost mass production and commercialization in the near future.

\section{Conflict of Interests}

The authors declare that there is no conflict of interests regarding the publication of this paper.

\section{Acknowledgment}

This study was supported by the National Science Council of Taiwan under Contract no. NSC 102-2221-E-024-012.

\section{References}

[1] A. Kirubakaran, S. Jain, and R. K. Nema, "Renewable and sustainable energy reviews," Renewable and Sustainable Energy Reviews, vol. 13, no. 9, pp. 2430-2440, 2009. 
[2] J. Kuo and C. Wang, "An integrated simulation model for PEM fuel cell power systems with a buck DC-DC converter," International Journal of Hydrogen Energy, vol. 36, no. 18, pp. 11846-11855, 2011.

[3] J. J. Hwang, "Review on development and demonstration of hydrogen fuel cell scooters," Renewable \& Sustainable Energy Reviews, vol. 16, no. 6, pp. 3802-3815, 2012.

[4] A. D. Hawkes and M. A. Leach, "The capacity credit of microcombined heat and power," Energy Policy, vol. 36, no. 4, pp. 1457-1469, 2008.

[5] J.-J. Hwang, P.-C. Wang, and J.-K. Kuo, "Simulation and experiment of a cogeneration system based on proton exchange membrane fuel cell," Fuel Cells, vol. 12, no. 3, pp. 326-334, 2012.

[6] R. A. Costa and J. R. Camacho, "The dynamic and steady state behavior of a PEM fuel cell as an electric energy source," Journal of Power Sources, vol. 161, no. 2, pp. 1176-1182, 2006.

[7] A. J. del Real, A. Arce, and C. Bordons, "Development and experimental validation of a PEM fuel cell dynamic model," Journal of Power Sources, vol. 173, no. 1, pp. 310-324, 2007.

[8] R. Tirnovan, A. Miraoui, R. Munteanu, I. Vadan, and H. Balan, "Polymer electrolyte fuel cell system (PEFC) performance analysis," in Proceedings of the IEEE International Conference on Automation, Quality and Testing, Robotics, (AQTR '06), pp. 457462, Cluj-Napoca, Romania, May 2006.

[9] J.-K. Kuo and C.-K. Chen, "The effects of buoyancy on the performance of a PEM fuel cell with a wave-like gas flow channel design by numerical investigation," International Journal of Heat and Mass Transfer, vol. 50, no. 21-22, pp. 4166-4179, 2007.

[10] T. Kim, S. Kim, W. Kim et al., "Development of the novel control algorithm for the small proton exchange membrane fuel cell stack without external humidification," Journal of Power Sources, vol. 195, no. 18, pp. 6008-6015, 2010.

[11] O. Rgab, D. L. Yu, and J. B. Gomm, "Polymer electrolyte membrane fuel cell control with feed-forward and feedback strategy," International Journal of Engineering, Science and Technology, vol. 2, pp. 56-66, 2010.

[12] M. Kim and H. Peng, "Power management and design optimization of fuel cell/battery hybrid vehicles," Journal of Power Sources, vol. 165, no. 2, pp. 819-832, 2007.

[13] A. Hajizadeh and M. Aliakbar-Golkar, "Fuzzy control of fuel cell distributed generation systems," The Iranian Journal of Electrical \& Electronic Engineering, vol. 3, pp. 31-41, 2007.

[14] J. J. Hwang and M. L. Zou, "Development of a proton exchange membrane fuel cell cogeneration system," Journal of Power Sources, vol. 195, no. 9, pp. 2579-2585, 2010. 

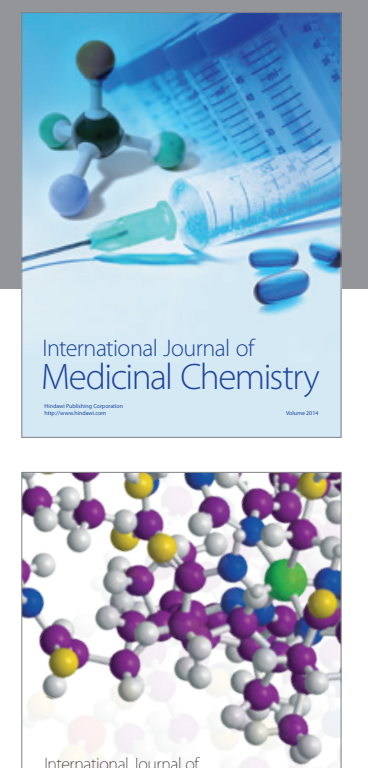

\section{Carbohydrate} Chemistry

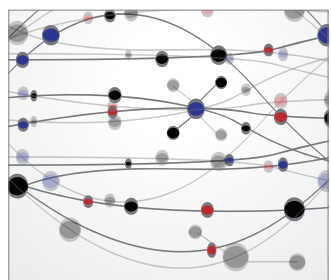

The Scientific World Journal
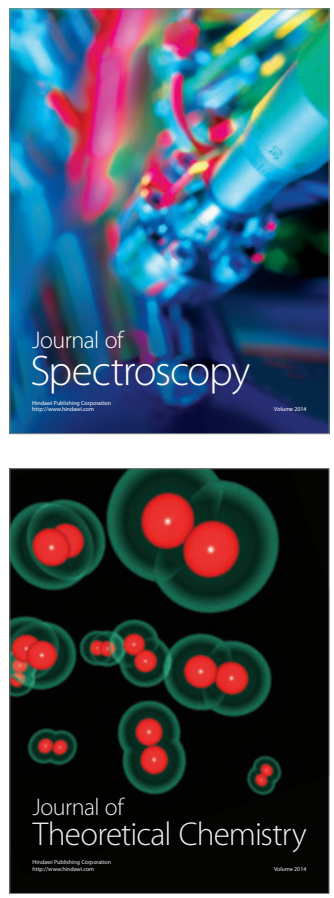
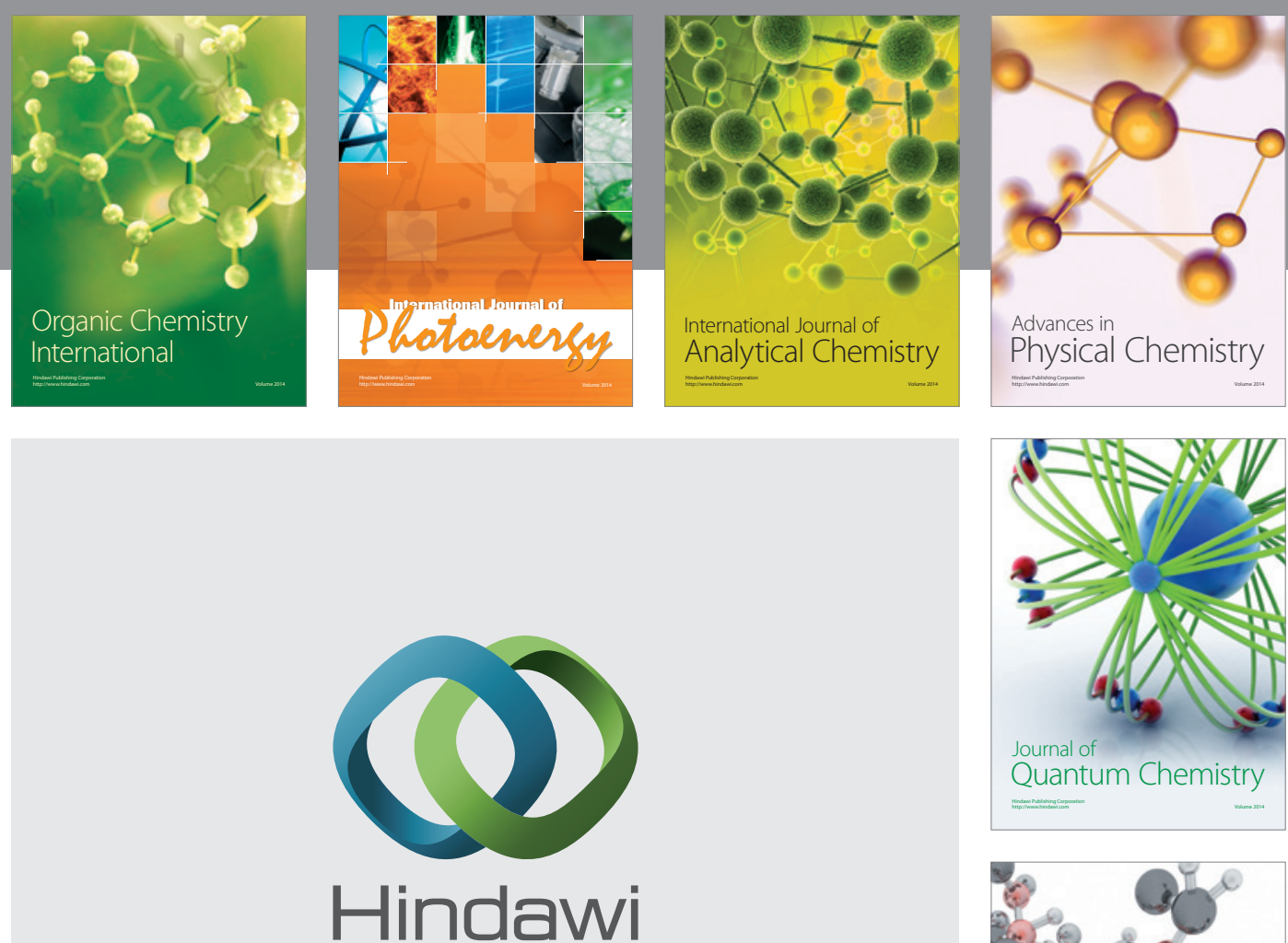

Submit your manuscripts at

http://www.hindawi.com

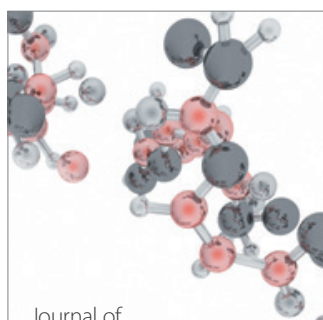

Analytical Methods

in Chemistry

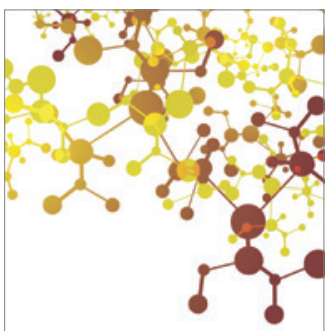

Journal of

Applied Chemistry

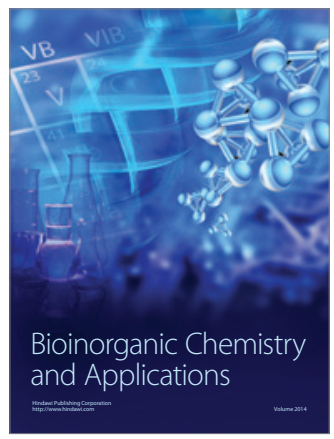

Inorganic Chemistry
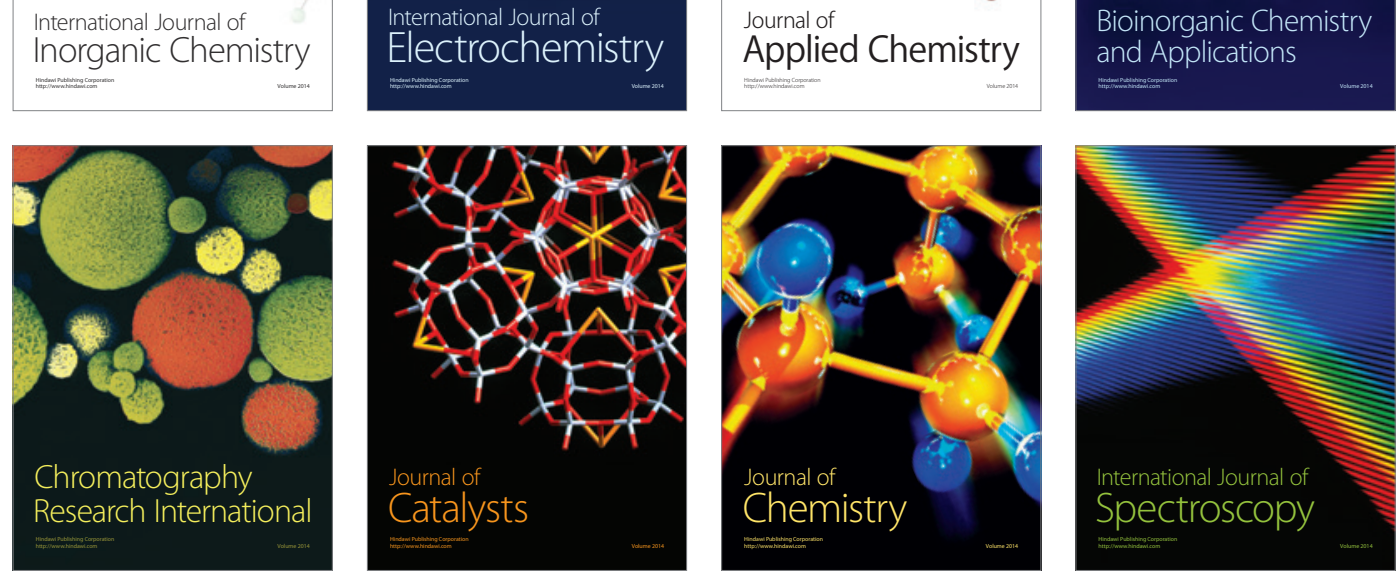